Discussion

The purpose of evaluating the hypothalamic-pituitaryadrenocortical (H.P.A.) function in glucocorticoid-treated patients is to select those patients with impaired function who will have to have supplementary glucocorticoids in stress situations.

Some authors have warned against the use of an ACTH stimulation test in the assessment of the H.P.A. function as it describes only the adrenocortical function and not the hypothalamic-pituitary function, which has been reported to be suppressed independently (Engel et al., 1958; Holub et al., 1959; Robinson et al., 1962; Brinck-Johnsen et al., 1963; Jasani et al., 1967). In some of these studies, however, the intense and prolonged ACTH stimulation may have promoted an adrenocortical response, which should not be compared to the response to the shorter and more physiological H.P.A. test.

The present investigation was carried out in order to show whether the response to a short stimulation with ACTH correlates with the integrated H.P.A. function during subsequent major surgery in glucocorticoid-treated patients. Our results show a high degree of correlation, and in no case was a normal preoperative response to ACTH followed by a greatly impaired H.P.A. response to surgery. In a similar study, Jasani et al. (1968) found a slightly impaired H.P.A. response to surgery in a few glucocorticoid-treated patients who showed a normal response to ACTH but a subnormal response to the insulin test. Obviously, the insulin test is the most sensitive test in the assessment of the H.P.A. function (Jasani et. al., 1967; Plumpton et al., 1969; British
Medical fournal, 1970). But based on the results of the present study it seems to us most unlikely that a preoperative normal response to ACTH will be followed by a greatly impaired H.P.A. response to major stress and it is concluded that a simple ACTH test is of value in predicting the integrated H.P.A. response to major stress in glucocorticoid-treated patients.

It is also to be expected that the ACTH test will be of value in patients previously treated with glucocorticoids, as the hypothalamic-pituitary system is restored before the adrenal cortex after cessation of glucocorticoid therapy (Graber et al., 1965).

\section{References}

Binder, C. (1972). Acta Endocrinologica (Kobenhavn), 69, 355

Brinck-Johnsen, T., Solem, J. H., Brinck-Johnsen, K., and Ingvaldsen, P. (1963). Acta Medica Scandinavica, 173, 129.

British Medical fournal, 1970, 1, 644.

Engel, E., Demenat, J. C., Brichant, J., and Riondel, A. M. (1958). Helvetica Medica Acta, 25, 552 .

Graber, A. L., Ney, R. L., Nicholson, W. E., Island, D. P., and Liddle, G. W. (1965). Fournal of Clinical Endocrinology and Metabolism, 25, 11 .

Holub, D. A., Jailer, J. W., Kitay, J. I., and Frantz, A. G. (1959). fournal of Clinical Endocrinology and Metabolism, 19, 1540.

Jasani, M. K., et al. (1967). Quarterly fournal of Medicine, 36, 261.
Jasani, M. K., et al. (1968). Ouarterly fournal of Medicine, 37, 407.

Kehlet, H., and Binder, C. (1973). British fournal of Anaesthesia. Submitted for publication.

Li, C. H. (1959). Science, 129, 969

Mattingly, D. (1962). Journal of Clinical Pathology, 15, 374.

Plumpton, F. S., Besser, G. M., and Cole, P. V. (1969). Anaesthesia, 24, 3. Robinson, H. B., Mattingly, D., and Cope, C. L. (1962). British Medical Fournal, 1, 1579 .

Treadwell, B. L. J., Savage, O., Sever, E. D., and Copeman, W. S. C. (1963). Lancet, 1, 355.

\title{
Induction of Labour in Sheep and in Humans by Single Doses of Corticosteroids
}

\author{
J. K. G. MATI, D. F. HORROBIN, P. S. BRAMLEY
}

British Medical fournal, 1973, 2, 149-151

\section{Summary}

In sheep the administration of single intramuscular injections of dexamethasone into the fetus was shown to be an effective method of initiating parturition. In a controlled trial in women who had gone beyond the 41 st week of pregnancy 20 mg betamethasone in saline (six patients) or saline alone (five patients) was injected into the amniotic fluid. In the betamethasone-treated group delivery occurred 78.9 \pm 10.2 (S.D.) hours after injection while in the control group it occurred $323 \pm 62$ (S.D.) hours after injection $(P<0.01)$. In one woman with an anencephalic pregnancy intra-amniotic injection failed to initiate parturition but delivery occurred 88.5 hours after intramuscular injection of betamethasone into the fetus.

University of Nairobi, P.O. Box 30197, Nairobi, Kenya

J. K. G. MATI, M.B., M.R.C.o.G., Senior Lecturer in Obstetrics and

D. F. HORROBIN, B.M., D.PHIL., Professor of Medical Physiology (At present: Reader in Physiology, University of Newcastle upon Tyne, Newcastle upon Tyne NE1 7RU)

P. S. BRAMLEY, B.v.SC., PH.D., Lecturer in Animal Physiology (Present address: Grassland Research Institute, Hurley, Maidenhead)

\section{Introduction}

The obstetric induction of labour presents particular problems in a developing country. All existing methods require careful observation of the mother between the beginning of the induction and delivery. This can place an almost intolerable pressure on an already overloaded service. We have therefore attempted to test a new method which can be carried out as an outpatient procedure and which allows the woman to return home until an apparently normal labour begins a few days later.

Liggins and his co-workers have been largely responsible for developing the concept that the secretion of cortisol by the fetal adrenal is a key factor in the initiation of labour (Liggins, et al., 1967; Liggins and Kennedy, 1968; Liggins, 1968, 1969). Fetal cortisol also seems to play a major part in lung maturation and a naturally initiated normal delivery is usually a good indication that the lungs are mature and that respiratory distress is unlikely (Howatt. et al., 1965; Liggins, 1968, 1969). Liggins showed that premature labour could be induced in sheep by infusion of glucocorticoids into the fetus and that the lambs born as a result of this procedure could sustain respiration at a stage in development when this was not normally possible. Intrauterine fetal infusion is clearly not a simple method of inducing labour, and we therefore attempted to show that in sheep a single injection of glucocorticoid into the fetus could initiate labour without obvious ill effects on either fetus or mother. Having done this, we also attempted by means of a con- 
trolled trial to test the effect of an intra-amniotic injection of a glucocorticoid on the initiation of labour in a group of women who had passed the 4lst week of pregnancy. We reasoned that since a normal fetus swallows amniotic fluid the steroid should gain access to the fetus by this route.

\section{Methods}

SHEEP

Twenty-three merino sheep with single pregnancies were used. Because of the known dates during which the ram was with the ewes the gestation duration in 19 of these animals must have been in the range 115-130 days while in the other four it must have been $\mathbf{1 5 0}$ days plus: precise dates for each sheep were not known. After starvation for 36 hours, anaesthesia was induced by sodium thiopentone and after intubation maintained by halothane. A vertical incision was made in the ewe's flank and, after checking that the pregnancy was indeed single, the hind leg of the fetus was grasped. An intramuscular injection of dexamethasone (Scanpharm) was given through the uterine wall into the hamstrings. In the 115-130 day group four animals received $5 \mathrm{mg}$ dexamethasone, six received $10 \mathrm{mg}$, and nine received $20 \mathrm{mg}$. All animals in the 150 days plus group received $20 \mathrm{mg}$.

\section{HEMANS}

Eleven normal pregnant women attending the antenatal clinic at Kenyatta National Hospital, Nairobi, were studied. All were of African origin. Before inclusion in the trial, all were carefully examined for any indication that labour might be imminent: in none of the women did the cervix show signs of softening or effacement. They had all reached the 41st week of pregnancy or later but had no urgent indications for induction apart from the possible dangers of prolonged pregnancy. None was Rh-negative. As an outpatient procedure, 5 $\mathrm{ml}$ of amniotic fluid was withdrawn by standard aseptic amniocentesis. The fluid was replaced either with $5 \mathrm{ml}$ sterile isotonic saline (five women) or $5 \mathrm{ml}$ sterile isotonic saline containing $20 \mathrm{mg}$ betamethasone (Schering) (six women). Alternate women received control or betamethasone injections. The women were observed for two hours to ensure that there were no immediate untoward effects and then allowed to go home. They were told to return when labour started or after one week if labour had not begun.

One patient (age 30, para $6+1$ ) with an anencephalic pregnancy was studied. She was referred from another clinic with mild hydramnios and a 49-week history of amenorrhoea. Anencephaly was suspected on the basis of clinical examination and confirmed by an $x$-ray picture. The fetus was still moving and heart sounds could be heard. A $20-\mathrm{mg}$ dose of betamethasone was administered by intra-amniotic injection but had no effect after one week. In view of this, $20 \mathrm{mg}$ was then given to the fetus intramuscularly through the maternal abdominal wall.

\section{Results}

\section{HUMANS}

The results are shown in table I. It is clear that this is an effective method of inducing parturition provided that an adequately large dose of dexamethasone is given. Of the four animals which were delivered spontaneously after a 10-mg dose of dexamethasone none respired spontaneously or had any evidence of lung aeration on postmortem examination. In contrast, of the nine premature lambs delivered after a fetal dose of $20 \mathrm{mg}$ eight showed some spontaneous respiration and lung aeration. This suggests that the higher steroid dose may have been more effective in producing premature lung maturation. All the four animals delivered near to normal full term breathed normally immediately after birth and were clinically healthy.

TABLE I-Results of Injecting Various Doses of Dexamethasone into Sheep Fetuses

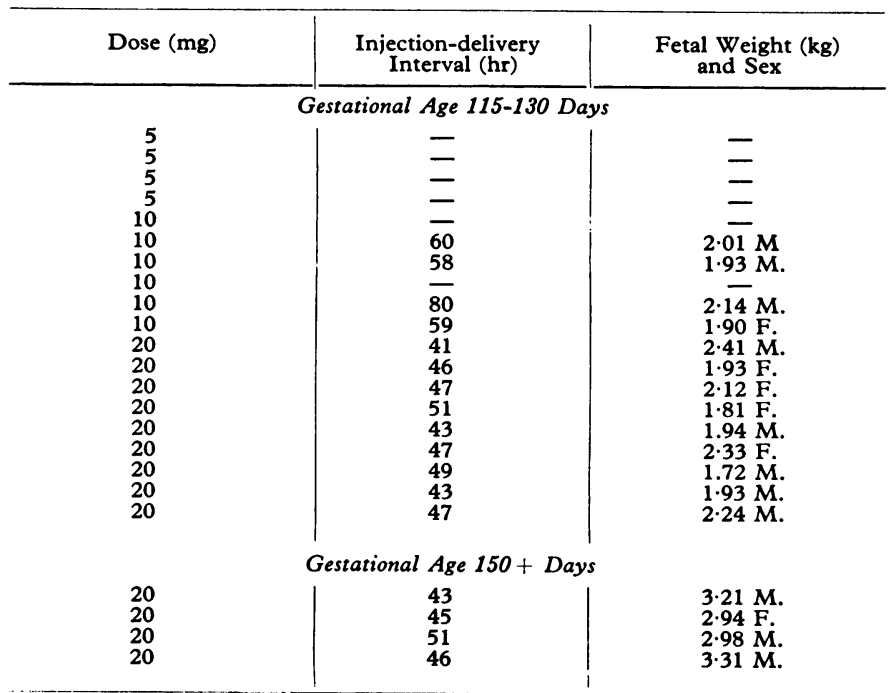

\section{HUMANS}

The results are summarized in table II. Again it is clear that the betamethasone injections accelerated the onset of labour: the difference in both induction-labour and induction-delivery intervals between the two groups is statistically highly significant $(P<0.01)$. In every case the labour which occurred after betamethasone seemed clinically indistinguishable from normal labour. Because of minor degrees of cephalopelvic disproportion one patient in each group was delivered by caesarean section after labour had been in progress for a few hours. The infants and mothers were all healthy and there were no ill effects detectable by clinical examination.

TABLE II-Results of Intra-amniotic Injection of Either $5 \mathrm{ml}$ Isotonic Saline Alone (Controls) or $5 \mathrm{ml}$ Isotonic Saline Containing $20 \mathrm{mg}$ Betamethasone

\begin{tabular}{|c|c|c|c|c|c|c|c|c|}
\hline Age & Parity & $\begin{array}{l}\text { Maturity } \\
\text { (weeks) }\end{array}$ & $\begin{array}{c}\text { Birth } \\
\text { Weight } \\
\text { (g) }\end{array}$ & Sex & Class* & $\begin{array}{l}\text { Induction- } \\
\text { labour (hr) }\end{array}$ & $\begin{array}{c}\text { Induction- } \\
\text { delivery } \\
\text { (hr) }\end{array}$ & $\begin{array}{l}\text { Delivery } \\
\text { Method }\end{array}$ \\
\hline \multicolumn{9}{|c|}{ Betamethasone Group } \\
\hline $\begin{array}{l}22 \\
25 \\
20 \\
19 \\
21 \\
28\end{array}$ & $\begin{array}{l}1+0 \\
4+0 \\
2+0 \\
0+0 \\
0+0 \\
5+0\end{array}$ & $\begin{array}{l}42 \\
43 \\
42 \\
41 \\
41 \\
41\end{array}$ & $\begin{array}{l}3,332 \\
3,276 \\
3,060 \\
3,360 \\
2,880 \\
2,968\end{array}$ & $\begin{array}{l}\mathbf{F} . \\
\mathbf{M} . \\
\mathbf{M} . \\
\mathbf{F} \\
\mathbf{M} . \\
\mathbf{F} .\end{array}$ & $\begin{array}{l}\mathbf{A} \\
\mathbf{A} \\
\mathbf{B} \\
\mathbf{A} \\
\mathbf{A} \\
\mathbf{A}\end{array}$ & \begin{tabular}{|l|}
113 \\
66 \\
$49 \cdot 75$ \\
$79 \cdot 25$ \\
$36 \cdot 75$ \\
$59 \cdot 75$
\end{tabular} & $\begin{array}{l}125 \\
76.5 \\
64.75 \\
95.75 \\
50.0 \\
61.5\end{array}$ & $\begin{array}{l}\text { S.V.D. } \\
\text { S.v.D. } \\
\text { C.S. } \\
\text { S.v.D. } \\
\text { S.V.D. } \\
\text { S.v.D. }\end{array}$ \\
\hline \multicolumn{3}{|c|}{ Mean \pm S.D. } & .. & .. & .. & $67 \cdot 4 \pm 24 \cdot 3$ & $78 \cdot 9 \pm 10 \cdot 2$ & \\
\hline
\end{tabular}

\begin{tabular}{|c|c|c|c|c|c|c|c|c|}
\hline & \multicolumn{8}{|c|}{ Saline Group } \\
\hline $\begin{array}{l}25 \\
20 \\
24 \\
26 \\
20\end{array}$ & $\begin{array}{l}5+0 \\
0+0 \\
2+0 \\
4+0 \\
0+0\end{array}$ & $\begin{array}{l}42 \\
42 \\
41 \\
41 \\
41\end{array}$ & $\begin{array}{l}3,010 \\
3,332 \\
3,752 \\
2,780 \\
3,353\end{array}$ & $\left|\begin{array}{l}\mathbf{F} . \\
\mathbf{M} . \\
\mathbf{M} . \\
\mathbf{F} . \\
\mathbf{M} .\end{array}\right|$ & $\begin{array}{l}\mathbf{B} \\
\mathbf{B} \\
\mathbf{A} \\
\mathbf{A} \\
\mathbf{B}\end{array}$ & $\begin{array}{l}480 \\
240.5 \\
167.5 \\
192 \\
480\end{array}$ & $\begin{array}{l}490.5 \\
260 \\
180 \\
197 \\
489.5\end{array}$ & $\begin{array}{l}\text { S.v.D. } \\
\text { C.S. } \\
\text { s.v.D. } \\
\text { s.v.D. } \\
\text { s.v.D. }\end{array}$ \\
\hline & \multicolumn{2}{|c|}{ Mean \pm S.D. } & .. & .. & .. & $312 \pm 142$ & $323 \pm 62$ & \\
\hline
\end{tabular}

-Classification of the newborn used in this study: $A=A$ baby that cries immediatel at birth and requires no resuscitation; $B=A$ baby that requires minimal resuscitation but cries within 10 minutes; $C=A$ baby that requires more intensive resuscitation but cries within 20 minutes; $D=$ Any baby that requires intubation or any baby alive within 20 minutes.

S.V.D. $=$ Spontaneous vaginal delivery. C.S. = Caesarean section. 
The exception to the effectiveness of intra-amniotic betamethasone was the woman with the anencephalic pregnancy. One week after the injection she showed no signs of beginning labour. It was reasoned that if the fetus had to absorb the drug for it to be effective then this would probably not have occurred because of defective swallowing. A 20-mg dose of betamethasone was therefore given intramuscularly to the fetus: labour began 86 hours later and was completed after 2.5 hours. The infant was a fresh stillborn anencephalic weighing $2,800 \mathrm{~g}$.

\section{Discussion}

The experiments in sheep showed that a single dose of dexamethasone could initiate labour provided that the dose was large enough. Lambs delivered near to the end of a normal pregnancy appeared clinically normal while those delivered prematurely appeared more able to breathe than premature lambs of the same age not treated with dexamethasone. Liggins (1969) found that the minimum total reliably effective dose of dexamethasone given by continuous infusion into the fetus was of the order of $0.4 \mathrm{mg}$. In contrast in this study a single dose of $10 \mathrm{mg}$ was only partly effective. This suggests that the fetal-maternal unit is able to eliminate the steroid very rapidly.

We thought that these findings made a trial of betamethasone in human pregnancy justifiable. The results were clear cut and left no doubt that betamethasone accelerates the onset of labour. There were no obvious ill effects in either mothers or babies, and if anything the treated infants (one in class $B$ and five in class A) were healthier at birth than those in the control group (three in class B and two in class A). The method therefore seems to warrant further trial on a larger scale. Betamethasone seems to be at least as safe as other drugs currently used to initiate labour and in some respects the method appears to have great advantages over existing techniques of labour induction. (1) The technique is simple and can easily be carried out as an outpatient procedure; (2) the patient can be allowed home and labour begins and is completed in an apparently normal way, which has obvious practical and financial advantages as well as psychological ones for the woman, who is not continually made aware that her labour has had to be induced; (3) the method is based on physiological principles and reduces the risk of a failed induction when oxytocic drugs or other methods of induction may be working against physiological mechanisms which are attempting to maintain the pregnancy; (4) the method uses a substance which is known to stimulate the maturation of normal lung function, thus reducing the risk of fetal respiratory distress; and (5) it may have particular advantages in highly parous patients and in those who have had a previous caesarean section in whom oxytocics may be dangerous.

We thank the Human Reproduction Unit of the World Health Organization for financial support for research in reproductive physiology, Professor D. A. M. Gebbie for permission to conduct the clinical trial in his department, Professor D. Robertshaw for the use of operating facilities in the department of animal physiology, and Mr. G. Kingabe for technical help.

Requests for reprints should be sent to: Dr. J. K. G. Mati, University of Nairobi, P.O. Box 30197, Nairobi, Kenya, or Professor D. F. Horrobin, University of Newcastle upon Tyne, Newcastle upon Tyne, NE1 7RU.

\section{References}

Howatt, W. F., et al., (1965). Clinical Science, 29, 239.

Liggins, G. C. (1968). Fournal of Endocrinology, 42, 323.

Liggins, G. C. (1969). Fournal of Endocrinology, 45, 515.

Liggins, G. C., and Kennedy, P. C. (1968). Fournal of Endocrinology, 40, 371 Liggins, G. C., Kennedy, P. C., and Holm, L. W. (1967). American fournal of Obstetrics and Gynecology, 98, 1080.

\title{
Persistence of Tanapox in Tana River Valley
}

\author{
P. E. C. MANSON-BAHR, A. W. DOWNIE
}

British Medical fournal, 1973, 2, 151-153

\section{Summary}

Sera collected from inhabitants of the Tana River valley in 1971 were examined for antibody to tanapox virus. Neutralizing antibody was present in $16.3 \%$. The levels of antibody and its presence in two children under the age of 10 years indicated that infection had been occurring in the area since the reported outbreak in 1962. A comparison of the incidence and distribution of antibodies in the same sera to West Nile virus revealed marked similarities suggesting that tanapox, like West Nile virus infections, might be transmitted in the same way-namely, by a culicine mosquito.

London School of Hygiene and Tropical Medicine, London W.C.1 P. E. C. MANSON-BAHR, M.D., F.R.C.P., Senior Lecturer

Department of Medical Microbiology, Liverpool University, Liverpool L69 3BX

A. W. DOWNIE, M.D., F.R.s., Emeritus Professor

\section{Introduction}

Outbreaks of tanapox in the Tana River area of Kenya were known to have occurred in 1957 and 1962 (Downie et al., 1971). In those years extensive flooding had occurred so that the local population were confined along with their domestic animals and wild animals to high ground which formed islands in the flood area. The disease is a relatively mild febrile infection associated with one or two firm pocks on exposed areas of skin. There is only one resident doctor at Ngao and records of clinical tanapox in the population since 1962 are not available. In 1971, however, blood specimens were collected by one of us (P.E.C.M.-B.) from members of the local population. Sera from these blood samples have been examined for antibodies to tanapox virus and other viruses, and sera from senior schoolboys in Tanzania have been examined to serve as controls. The results suggest that tanapox has continued to occur in the Tana River area since the outbreak of 1962 .

\section{Materials and Methods}

The sera were tested for neutralizing antibodies against tana- 